\title{
LAS FALLAS DE VALENCIA: EL ARTE DE LA CONSAGRACIÓN DEL FUEGO ${ }^{1}$
}

\author{
Xavier Costa
}

Universidad de Valencia

\begin{abstract}
RESUMEN
En la primera parte de esta nota me ocupo de algunos aspectos que articulan la fiesta y el arte en la hermenéutica. La idea fundamental es que el arte tiene su lugar en el evento de apropiación (Ereignis) que acontece en la Fiesta. En la segunda parte sitúo la tradición festiva de las Fallas en el contexto de la transformación ritual de los antiguos festivales ígnicos del cambio estacional. La antigua conexión mítica, ambigua, entre la víctima y el dios, típica del sacrificio agrario del dios, es puesta ahora en términos artísticos, poemáticos y fantásticos. La víctima y el dios se han transformado en la co-pertenencia del arte y del fuego en la Fiesta. El cuidado de la comunidad festiva, que "guarda la llama» de la Fiesta, es entendido como sociabilidad (Simmel) en la tercera sección, donde describo brevemente el "pique satírico» como ejemplo de tipificación que no opone la crítica al juego, al arte y al humor en los procesos de reconocimiento inscritos en la sociabilidad festiva. Finalmente me ocupo del monumento efímero, de su impacto sobre la sociabilidad, de su esfera pública y de algunas manifestaciones colectivas, como el duelo y la melancolía, que se producen durante la cremà, el momento trágico en que el arte retorna al fuego, repitiendo cíclicamente un "curso civilizador» que devuelve el sentido de la cultura a aquellos que participan, y se forman, en la Fiesta.
\end{abstract}

${ }^{1}$ Esta nota elabora algunos aspectos de un reciente estudio sobre Las Fallas que estoy acabando de escribir en estos momentos bajo la direccion del profesor James A. Beckford, de la Universidad de Warwick (UK). 


\section{FIESTA Y ARTE EN LA HERMENÉUTICA}

La fiesta, para la hermenéutica, constituye un camino de acceso al mundo. A diferencia de otras escuelas, que se preocupan por la fiesta como un tema más entre otros, Heidegger entiende como una fiesta, al modo festivo, el propio movimiento de pensamiento que sabe permanecer en el círculo hermenéutico. El camino hermenéutico es el camino de la celebración: «adentrarse por este camino es una señal de fuerza y permanecer en él es la fiesta del pensar $»^{2}$. La hermenéutica propone una vuelta al antiguo sentido de la teoría: en Grecia recibía el nombre de teórico aquel que viajaba como delegado a una celebración. La naturaleza conmemorativa de la fiesta, que hace memoria, forma parte así del "pensamiento conmemorativo" del teórico. De aquí que el tema de la memoria, Mnemosine, sea fundamental para la hermenéutica.

El pensamiento conmemorativo gana acceso al mundo mediante una intimidad con las cosas. De nuevo aquí encontramos la fiesta en su camino. En la fiesta tiene lugar la originaria relación recíproca entre los dioses y los mortales. Esta «fiesta nupcial de hombres y dioses» produce Ereignis ${ }^{3}$, una vuelta de apropiación que renueva las cosas al aproximar intensamente a los Cuatro del Mundo: cielo, tierra, mortales y divinos. Este vuelco respecto a lo primordial, y propio, de una comunidad, que aproxima y vincula, intensifica la mirada de la Memoria en la fiesta. Nos permite recordar más, al tiempo que abre y redefine epocalmente el mundo. Pero este poder de congregación, de aproximación y de vinculación que tiene la fiesta, no suprime las diferencias. Más aún, la celebración constituye un punto desde el cual apreciar aquello que se ha convertido en rutina, o dura ley identificante, en el «dispositivo» (Ge-stell $)^{4}$.

Queremos saber ahora cómo pueden articularse fiesta y arte para poder dar cuenta de una fiesta tan significativamente artística como las Fallas. Me voy a referir aquí solamente a cuatro dimensiones del arte en las Fallas que cabe articular con la fiesta. En primer lugar, hay una sociabilidad, de naturaleza lúdica y artística, que sostiene la fiesta y cuida de la periódica erección de la obra, del monumento. En segundo lugar, nos encontramos ante el monumento efímero, como centro de un ritual de ofrecimiento. En tercer lugar, fiesta y arte se encuentran en un sentido peculiar del tiempo. Finalmente, fiesta y arte tienen una relación con el sueño y con el chiste.

Las reglas que prevalecen, y vinculan, en la Fiesta no se asemejan a las que rigen en el «querer de autoimposicion» característico de la voluntad del sujeto soberano del «dispositivo». Éstas proceden, para Heidegger, de una manifestación del ser a través del juego y de la danza ${ }^{5}$, que presiden el modo en que los

2 M. Heidegger, Caminos del bosque, Alianza, Madrid, 1995, p. 12.

3 M. Heidegger, Caminos del bosque, Alianza, Madrid, 1995, p. 243, y M. Heidegger, Gesamtausgabe, 52, Vittorio Klostermann, Frankfurt am Main, 1982, p. 77.

${ }^{4}$ M. HeidegGer, Gesamtausgabe, 52, Vittorio Klostermann, Frankfurt am Main, 1982, p. 64.

5 M. Heidegger, Gesamtausgabe, 52, Vittorio Klostermann, Frankfurt am Main, 1982, p. 67. 
Cuatro del Mundo se aproximan, y entran en relación mutua, para recrear el Mundo y las cosas. Igualmente el canto del rapsoda representa un modelo de respuesta no instrumental que "escapa a toda autoimposicion intencional» ${ }^{6}$. Éstas y otras manifestaciones expresivas y artísticas no pueden reducirse a lo "objetivo del mundo" ${ }^{7}$. Constituyen una expresión jocosa y vinculante del ser, y dan a la fiesta su alegría característica, convirtiéndola en cumbre donde la mirada de Mnemosine detecta las separaciones y clasificaciones de la torre de vigilancia panóptica. Las actividades que constituyen la rica sociabilidad festiva permanente de las Fallas son esencialmente de esta naturaleza no-instrumental. Constituyen un saber que permite mantenerse en lo abierto, dando a una comunidad la posibilidad de participar en la construcción de la Fiesta y de cuidar de sus aspectos artísticos. El desafío consistente en plantar anualmente un monumento es atendido mediante este ejercicio festivo de la sociabilidad, caracterizada por el juego, el humor, el comensalismo y el arte.

El arte se encuentra también en las Fallas en el centro del ritual festivo, como monumento efímero, que va a ser ofrendado y destruido en una catarsis de fuego. En este sentido cabe situar en primer lugar a las Fallas en relación con la tragedia y el duelo. En segundo lugar puede observarse su papel como centro del ritual de ofrecimiento, donde tragedia y duelo se manifiestan. En cuanto a lo primero, la fiesta es el "fundamento de la alegría y del duelo» ${ }^{8}$. Ciertamente, como veremos después, estos elementos aparecen en la fiesta de las Fallas, aunque en nuestra Fiesta existen también otros aspectos asociados a aquéllos. Me refiero a la sátira y a la melancolía. En las Fallas la tragedia aparece revestida como sátira y el duelo se encuentra acompañado de melancolía. En cuanto a lo segundo, puede afirmarse que el monumento de arte efímero se encuentra exactamente en ese punto del ritual festivo que es el centro del evento de apropiación, Ereignis, el punto que señala el ofrecimiento mutuo entre dioses y mortales. Representa así la manera heideggeriana de comprender el arte: «El arte no se entiende ni como ámbito de realización de cultura ni como una manifestación del espíritu: tiene su lugar en el Ereignis, lo primero a partir de lo cual se determina el "sentido del ser" ". Una observación más me permitirá explicar la relación que existe entre la Falla, como monumento efímero ofrendado al fuego, y lo que la hermenéutica entiende como esencia del arte. Cuando Heidegger proporciona un ejemplo de lo que significa el «poner» de la obra de arte — para diferenciarlo del sentido moderno del "poner», como fija-

${ }^{6}$ M. Heidegger, Caminos del bosque, Alianza, Madrid, 1995, p. 285.

Estas actividades son parte constituyente de lo que Heidegger denomina el Poema en sentido general. Al participar en ellas se enfrenta un riesgo, comprometiéndose en un rememorar más: «la interiorización rememorante invierte la separación y permite entrar en el más amplio círculo de lo abierto», M. Heidegger, Caminos del bosque, Alianza, Madrid, 1995, p. 279.

${ }^{8}$ Heidegger discutió el papel de la tragedia y el fuego en la fiesta en relación con la obra de Hölderlin (en M. Heidegger, Gesamtausgabe, 52, Vittorio Klostermann, Frankfurt am Main, 1982, p. 71.)

9 M. Heidegger, Caminos del bosque, Alianza, Madrid, 1995, p. 73. 
ción rígida, inmóvil y segura de la composición de armazón, del «dispositivo»— se refiere exactamente al "poner» entendido como traer hacia lo no oculto una estatua, como ofrenda sagrada. En ese contexto añade: «El alzarse de la estatua (es decir, la presencia del resplandor que nos contempla) es diferente del alzarse de eso que se alza enfrente al modo del objeto. "Erigirse, establecerse" es la constancia del resplandecer» ${ }^{10}$.

Este significado de "erigir" la estatua que se ofrenda, como presencia de un resplandor, permite entender el modo en que el arte del monumento se pone en relación con el resplandecer del fuego sagrado, con la intensa sociabilidad comunitaria del tiempo festivo y con la representación del mundo que realiza a nivel de crítica satírica en la esfera pública. Instalar o erigir una obra es tambien consagrar y glorificar: "Consagrar significa sacralizar en el sentido de que, gracias a la erección de la obra, lo sagrado se abre como sagrado y el dios es llamado a ocupar la apertura de su presencia. De la consagración forma parte la glorificación, en tanto que reconocimiento de la dignidad y el esplendor del dios» ${ }^{11}$. En este sentido la instalación de la Falla en la plaza es ya una llamada para la presencia del fuego, para su consagración y glorificación. Al mismo tiempo el monumento, como toda obra de arte, levanta un mundo:

«... articula y reúne a su alrededor la unidad de todas esas vías y relaciones en las que nacimiento y muerte, desgracia y dicha, victoria y derrota, permanencia y destrucción, conquistan para el ser humano la figura de su destino. La reinante amplitud de estas relaciones abiertas es el mundo de este pueblo histórico; sólo a partir de ella y en ella vuelve a encontrarse a sí mismo para cumplir su destino»" ${ }^{12}$.

En las Fallas este mundo es presentado mediante las escenas satíricas del monumento, que constituyen un modo de comprender la esfera pública. Finalmente, el monumento interacciona con la sociabilidad festiva a dos niveles. Por una parte, es la obra a cuidar por parte de la comunidad, que intensifica notablemente su sociabilidad durante el tiempo anterior a su erección, y despliega un programa de fiestas. Pero, al mismo tiempo, esta sociabilidad es también afectada por el monumento mismo, aumentando así su efervescencia y movilidad. La nueva apertura de vías y relaciones que expone el monumento incide de varios modos en la intensificación de la sociabilidad, ya acrecentada mediante el cuidado. Uno de estos modos, como mostraré después, es el de la configuración de lo que en psicoanálisis se denomina «un polo de atracción preliminar», que actúa como catalizador de la sociabilidad festiva, especialmente en todo lo relacionado con el juego y el humor.

${ }^{10}$ M. Heidegger, Caminos del bosque, Alianza, Madrid, 1995, p. 71.

11 M. Heidegger, Caminos del bosque, Alianza, Madrid, 1995, p. 36.

12 M. Heidegger, Caminos del bosque, Alianza, Madrid, 1995, p. 34. 
Había señalado anteriormente que la tradición festiva une al tiempo que mantiene las diferencias. Una de las formas en que esta naturaleza de la fiesta se manifiesta con claridad tiene que ver con el tiempo: la fiesta pone en relación de simultaneidad a los diversos tiempos, que interaccionan en ella. Gadamer entiende la condición existencial humana a través de la capacidad para la "unificación de pasado y presente, en la simultaneidad de los tiempos, los estilos, las razas y las clases», que nace y crece como Memoria, el secreto de la tradición para dar permanencia a lo fugitivo ${ }^{13}$.

El tiempo cíclico vertebra la tradición festiva. El tiempo fundamental de las Fallas es el tiempo de la representación mítica de la renovación del mundo, que acompaña a la eclosión del ser. El momento de recreación es el de la aparición catártica del fuego en la cremà. En las Fallas existe un Año Fallero, y un calendario que acuerda el ritmo festivo con las transformaciones estacionales. Pero la repetición del ciclo de la tradición festiva no es mera conservación sino transmisión, puesta al día, traducción para el hoy, aprendizaje para concebir y expresar las cosas de nuevo en el momento presente ${ }^{14}$. Así, por ejemplo, tras cada ejercicio fallero, los participantes dicen esforzarse «por hacer las cosas mejor el año próximo». De este modo la tradición es siempre innovación en un mundo que se recrea periódicamente: es el aprendizaje de la renovación efectiva de la experiencia.

Este aprendizaje activo de la tradición festiva da, además, un sentido a la comunidad y al sujeto sobre su propia condición. El punto donde este aprendizaje se manifiesta con más evidencia es el momento de la cremà. Como señalaré después, los aspectos de la tragedia que conserva la sátira artística del monumento, y la cíclica repetición asociada al duelo y a la melancolía, renuevan el sentido de la finitud, un saber que permite distanciarse humanamente de la perspectiva de fusión con la naturaleza y de la hibris en la relación con lo sagrado. Pero la sociabilidad festiva permanente atiende también a este sentido del tiempo que, según Gadamer, acerca a la fiesta y al arte. Este «tiempo propio" es un tiempo lleno, que invita a demorarse para retener lo efímero, lo fugitivo, el sentido de la finitud ${ }^{15}$. Una fiesta tan artística como las Fallas sabe doblemente de este tiempo. Algunos de sus símbolos fundamentales pueden evidenciarlo para un observador no participante: las flores, la música, el estallido de colores de la carcasa, el arte del monumento efímero. Al ser preguntado por la presencia de las flores en la Fiesta, un experimentado fallero señaló: «Están unidas a la Fiesta. Hay tres o cuatro cosas que, si no estuvieran, no sería posible comprender la Fiesta: traca, música, flores. Si a esto le añades que las flores son algo efímero, que su vida es corta y que pueden romperse fácilmen-

${ }_{13}$ H. GadAmer, La actualidad de lo bello, Paidós, Barcelona, 1991, p. 112.

${ }_{14}$ H. Gadamer, La actualidad de lo bello, Paidós, Barcelona, 1991, p. 116.

15 H. Gadamer, La actualidad de lo bello, Paidós, Barcelona, 1991, pp. 103 y ss. Heidegger se refiere al tiempo de marzo al hilo de su discusión de la Fiesta en relación con Hölderlin. Märzenzeit es el tiempo de lo efímero, transitorio y perecedero (Gesamtausgabe, v. 52, Vittorio Klostermann, Frankfurt am Main, p. 83). 
te, como las otras cosas de la Fiesta, pues ya lo tienes». Pero este sentido de lo efímero corresponde con un momento de eternidad. Supone la sensación de tener «todo el tiempo del mundo» en un instante lleno, que pasa fugitivamen$\mathrm{te}^{16}$. El tiempo festivo se presenta como completo, se vive como lleno y, cuando pasa, es sentido como escaso, corto, efímero, en relación con lo lleno que es mientras se vive. Sin embargo, como en el caso del tiempo de una pieza musical, las Fallas tienen su propio tiempo, que interpretan los participantes. Se trata, además, del mismo tiempo tanto para la Fiesta como para el monumento. La Fiesta dura mientras el monumento artístico está en pie, y en ambos casos la preparación, o construcción, es anual. Además, los actores festivos señalan siempre que no sería posible disponer de un día más de Fiesta, que su duración es la justa: «es exactamente el tiempo que aguanta el cuerpo». El tiempo propio de la comunidad festiva es, pues, también el tiempo del arte en la Falla.

Finalmente, existen otros dos aspectos que aproximan la fiesta y el arte, y que han sido discutidos por la hermenéutica y el psicoanálisis. Me refiero al chiste y al sueño. No puedo extenderme aquí en un largo comentario. Baste señalar que en el psicoanálisis constituyen piezas angulares de la manifestación de la historia del sujeto en la transferencia. En el psicoanálisis el sueño es una elaboración equívoca que actúa como satisfacción de un deseo latente. En este sentido presento más adelante la idea de Freud de que el sueño diurno, que aparece en la fiesta y en el arte, es una sustitución del juego infantil, que aparece bella y equívocamente presentado, dando así un cumplimiento sustitutivo al deseo ${ }^{17}$.

\section{LA PUESTA AL DÍA DE UNA TRADICIÓN}

El olvido de este sentido de la tradición como puesta en relación de los tiempos, que aproxima la memoria, y produce una renovación efectiva, una «transmisión de las cosas», podría hacer pensar que las Fallas son una fiesta

${ }^{16}$ Esta sensación del tiempo se tiene incluso en las circunstancias en que hay que trabajar para la Fiesta. Se trata de un trabajo que está vinculado a la sociabilidad festiva, y se entiende de modo totalmente diferente al trabajo realizado en la jornada laboral. Una vez fue necesario reparar un armario del casal. Una de las tres personas del grupo era oficial de carpintería y un gran fallero. Lejos de atender la faena desde la perspectiva profesional, Amado nos invitó a enroscar un tornillo poco a poco, disfrutando de cada instante. Fue una Fiesta: hicimos turnos espontáneamente para sujetar la puerta, manejar el destornillador y contar anécdotas chistosas. ¡Nadie sabe el tiempo que paso! Amado dijo: «Aquí tenemos todo el tiempo del mundo». El tiempo festivo daba cabida a su tiempo propio. Su corazón, ya enfermo, lo buscaba allí, en la Fiesta, fuera del taller. Amado murió unos meses después. Le estalló el corazón mientras hacía su jornada regular de trabajo en la carpintería.

${ }_{17}$ El sueño, además, tanto en la hermenéutica como en el psicoanálisis, se asocia con la memoria. Así, Heidegger concluye su discusión de la Fiesta mostrando su vinculación con el sueño, como medio que permite una manifestación ambigua de aspectos del ser. En M. HeIDEGGER, Gesamstaugabe, v. 52, Vittorio Klostermann, Frankfurt am Main, 1982, pp. 107 y ss. 
exclusivamente moderna. De hecho la Fiesta incorpora una gran cantidad de nuevos elementos, que integra el viejo ritual ígneo desde el siglo XVIII hasta el momento actual. Algunos de éstos son el asociacionismo voluntario, ciertos aspectos de la racionalidad económica, los nuevos materiales de construcción del monumento, las escenas de la política actual, etc. Sin embargo, el abigarrado pastiche de la Fiesta, cuya capacidad para el sincretismo sorprende, obliga a leer de otro modo la "traducción» que elabora la tradición de las Fallas. Las formas básicas de la sociabilidad festiva, los mitos o los viejos símbolos del monumento, la sátira, la dinámica del ritual, etc., aparecen siempre de nuevo como la semilla reproductora que salta hacia el presente ${ }^{18}$. Heidegger y Gadamer gustan de poner el ejemplo del monumento, tan pertinente en el caso de las Fallas, para explicar esa interacción en el tiempo que es la tradición: «la tarea de poner juntos el hoy y aquellas piedras del pasado que han perdurado es una buena muestra de lo que es siempre la tradición. No se trata de cuidar los monumentos en el sentido de conservarlos; se trata de una interacción constante entre nuestro presente, con sus metas, y el pasado que también somos» ${ }^{19}$. Las Fallas son, pues, una tradición que se renueva al tiempo que incorpora sincréticamente elementos de la experiencia presente, algunos de los cuales caracterizan a la modernidad. Las Fallas, sin embargo, no traducen para la comprensión moderna de la existencia. Así, por ejemplo, tienen elementos, tanto en el monumento como en su sociabilidad satírica y callejera, que pueden perturbar la delicadeza de gusto, la mirada optimista hacia el progreso y la formalidad o seriedad de muchos "burgueses civilizados». Esto no significa que las Fallas sean "conservadoras", pues cada año vierten su nueva versión sobre el mundo. Se diferencian así de otros rituales del fuego típicamente conservadores, como el de Gwy Fawkes, en Inglaterra, que mantiene siempre el mismo personaje para quemar. La figura que todavía hoy protagoniza una buena cantidad de rituales ígneos, el simple pelele de paja y trapo, desapareció hace mucho tiempo del ritual fallero.

Las Fallas, como tradición, han realizado una transformación artística del antiguo pelele y de los viejos festivales ígnicos rurales de Europa. El origen del muñeco puede dar luz sobre el modo en que se conduce esta tradición festiva valenciana. Frazer realizó una interpretación de los festivales ígnicos en una gran obra, La Rama Dorada. La figura del muñeco que se quema aparece aquí vinculada al rey efímero, asociado a las viejas divinidades de la vegetación, que es sacrificado periódicamente como víctima propiciatoria para la purificación de la comunidad y la renovación de la naturaleza ${ }^{20}$. Una

18 Ricardo Sanmartín se refiere a la tradición como «semilla del presente» en «Cambio y tradición. Historia y modernización en la Comunidad Valenciana», Revista de Antroplogía Social, n. ${ }^{\circ}$ 5, Universidad Complutense, Madrid, 1996, pp. 128-129.

19 H. Gadamer, La actualidad de lo bello, Paidós, Barcelona, 1991, p. 117.

${ }^{20}$ Frazer defiende la teoría "purificatoria» para explicar los Festivales del Fuego a lo largo de toda su obra. Pero en el cap. V de la parte VII, vol. I, de The Golden Bough (Macmillan, London, 1963), se discute específicamente esta cuestión. La relación entre la muerte del dios y los Carnavales puede encontrase en el vol. VI, titulado significativamente The Scapegoat. 
variedad de festividades, entre ellas el Carnaval, destruyen estas figuras ${ }^{21}$. Hubert y Mauss dedican a este rey-dios, que es representado también como víctima de modos diversos, la parte final de su conocida obra sobre el sacrificio $^{22}$. Señalan que su objetivo es el de añadir nuevos hechos a las ya existentes consideraciones de Frazer y de Mannhardt, que asociaban el sacrificio del dios con los sacrificios agrarios. El sacrificio del dios es de naturaleza mitológica y presenta, entre otras características, una afinidad entre la naturaleza de la víctima y el dios, que permite a éste pasar al papel de aquélla, desdoblándose ambiguamente gracias a la plasticidad de la narrativa del mito. Esta transformación garantiza la periódica resurrección de la víctima, y el renacimiento del dios, en función del ritmo cíclico de la naturaleza. Este ritual sacrificial se encuentra detrás, en una versión purificada, de la misa cristiana, pero también cabe encontrarlo en otras versiones más o menos deformadas por la imaginación mítica popular: leyendas, dramas sacros, procesiones, etc. En estos casos «los episodios míticos están generalmente vinculados a ceremonias rituales».

Las Fallas se originan como una versión peculiar de representación de este sacrificio mítico. Mantienen las «viejas piedras» en su representación, tanto en la sociabilidad festiva como en el monumento: el juego, el humor, el comensalismo, el muñeco (ninot), el fuego, etc., se encuentran hoy en la Fiesta. Además, los actores festivos sostienen aún el sentido purificador del ritual, y lo hacen explícito discursivamente ${ }^{23}$. Pero la antigua violencia sacrificial se ha transformado en crítica satírica, arte y ensoñación festiva, y el lugar de la víctima es ocupado ahora por un monumento efímero, construido para el fuego. Estos aspectos, a los que también se refieren los participantes, constituyen algunos de los ejes de las «nuevas piedras» de la tradición fallera, que interaccionan con las viejas en la dinámica de la Fiesta. Esa interacción se asienta en el poder de vinculación de la sociabilidad festiva, que congrega a los miembros de una comunidad que cuida la tradición. La efervescencia de la reunión festiva está caracterizada por el juego y sus derivaciones: la poesía y el arte, el humor, la fantasía diurna.

${ }^{21}$ Freud se refirió también a las representaciones que incluían este muñeco, utilizando los estudios de Frazer, para ponerlas en relación con su hipótesis de la repetición simbólica de la muerte del padre de la horda primitiva. Freud se refiere aquí también a los estudios de Robertson Smith, que entiende el sacrificio de una divinidad como tragedia mítica (Totem y Tabú, Alianza, Madrid, 1967, pp. 196 y ss.).

${ }^{22}$ H. Hubert y M. Mauss, Essai sur la nature et fonction du sacrifice. M. Mauss, Oeuvres, I, (Les Éditions de Minuit, Paris, 1968, pp. 283 y ss.).

${ }^{23}$ Los actores festivos señalan el arte y la crítica como elementos que diferencian a las Fallas de los otros fuegos rurales. El sentido de purificación catártica por el fuego se articula hoy con los símbolos artísticos del monumento. Como señaló un experimentado fallero: «La Falla tiene su origen en la crítica. Años atrás era quemar todo lo viejo, como quemar rencores. Se quemaba todo eso, como quemar la envidia. A continuación se le pegaba fuego al símbolo de la Falla. Entonces es como si hubieras hecho una limpieza, bajo el símbolo de la Falla arden toda la envidia, rencillas, mil cosas». 
Freud articuló la fantasía o ensoñación diurna con la creación poética y con la imaginación mítica, mostrando que constituyen un sustitutivo de los juegos infantiles y un goce artístico que actúa como placer preliminar que «descarga nuestra alma». Como en el sueño nocturno, este goce artístico da salida y satisfacción a los deseos reprimidos de un modo deformado y mitigado, elaborados como manifestación artística ${ }^{24}$. Las Fallas constituyen así una fiesta que pone en términos artísticos, poemáticos y fantásticos la antigua conexión mítica ambigua entre la víctima y el dios del viejo sacrificio agrario. La víctima y el dios devienen arte y fuego en la fiesta. En las Fallas arte y fuego se co-pertenecen, y se manifiestan el uno en el otro ${ }^{25}$. El arte de la sociabilidad festiva y del monumento tienen como término el fuego. Por otro lado, el fuego ya está presente en el movimiento de preparación de la Fiesta y en la construcción de las figuras del monumento. Así, el arte desvela en la Fiesta una parte de su misterio, y el participante sabe periódicamente de su humana finitud ofreciendo sus artes al fuego.

\section{ARTE, JUEGO Y HUMOR EN LA SOCIABILIDAD FESTIVA}

Simmel encontró en la sociabilidad, como dimensión de la vida social, las mismas características del juego y del arte ${ }^{26}$. Las Fallas gozan de una intensa sociabilidad festiva permanente, caracterizada por su capacidad para reunir a los participantes en el juego, el humor y el comensalismo. Familias, grupos de amigos y de vecinos constituyen sus células fundamentales. Esta sociabilidad festiva sostiene el proyecto compartido de la Fiesta, e incorpora el trabajo colectivo como parte, destinada a la obtención de recursos para la celebración.

La sociabilidad está situada en una comunidad festiva: «La Falla es una comunidad de gente». Algunas expresiones que abundan entre los participantes para referirse a su naturaleza es la de «reunión de gente», "grupo de gente que quiere pasárselo bien juntos", "grupo de personas cuyo objetivo es pasárselo bien y continuar una tradición», "pequeño mundo reunido», "centro de reunión», etc. Los participantes siempre enfatizan un especial sentido de unión en la tarea común y la cordialidad, que asocian a un «buen ambiente» en el que «la alegría, el buen humor y el ambiente» predominan. La reunión efervescente es el espacio en que brota la fiesta: "las reuniones son un follón, uno dice una cosa, el otro una tontería, un chiste, y ya está la fiesta montada». Los falleros se

${ }^{24}$ E. Freud, Obras completas, vol. VI, Orbis, Barcelona, 1988, p. 1348.

${ }_{25} \mathrm{Al}$ ser preguntado por el sentido de los ninots, de las caricaturas, de la ironía y de la sátira del monumento, un fallero muy experimentado indicó: «Todo eso va implícito en el fuego. Incluso cuando se hacían las primeras fallas, las primeras hogueras, entonces se llamaban hogueras, se plantaba un ninot, o se hacía una simulación con un ninot, lo demás eran trastos viejos. Pero ya se hacía un ninot, como todavía se hace hoy en otras fiestas que ... ahora no recuerdo. Se ponen ninots en el barrio para criticar y después se queman»

${ }^{26}$ G. SimmeL, "Sociability», in Wolf, Kurt H., ed., The Sociology of George Simmel, The Free Press, London, 1950, pp. 40 y ss. 
reúnen para una gran variedad de actividades: comer, beber, charlar, jugar a las cartas (dominó, etc.), ensayar teatro, preparar play-backs o karaoke, disfrazarse, ensayar baile folclórico o de salón, tocar con la banda de música, participar en competiciones deportivas, ver la televisión, organizar loterías y rifas, programar la Semana de Fallas, arreglar el casal, etc., etc.

La identidad social y las condiciones de fallero se entienden en relación con el nivel de integración y compromiso respecto a esta comunidad festiva, que se manifiesta en la participación en las actividades que constituyen su sociabilidad festiva permanente. Así, la sociabilidad festiva diferencia claramente a los que "están ahí» plenamente en la tarea colectiva y los que no están tan entregados a la misma. Como señaló un fallero, director de una banda de música: «Los que van al casal los viernes, y están allí con la cena, con su bocadillo, y hacen sus partiditas, durante todo el año, ésos mantienen el espíritu vivo, la llama, de la Fiesta. Luego hay gente, los falleros de cuatro días, que nada más vienen al final». Otras diferencias que coexisten pierden, o desdibujan, sus relevancias como potenciales fuerzas de desunión en este contexto dominado por la naturaleza no-instrumental de la sociabilidad y de la Fiesta. En este sentido, las Fallas se han convertido en lugar de integración de inmigrantes, en espacio de aproximación entre las generaciones, en ámbito de solapamiento de pandillas de amigos, etc. Merece la pena insistir en que esto no significa que deje de haber diferencias, sino que hay un impulso que las articula, con mayor o menor éxito cada año, en la obra común. La tarea filosófica de averiguar si primero es la "diferencia» o la «unión» no tiene sentido en el marco de la sociabilidad. El nivel de "armonía», incluso de unidad transitoria, depende de un proceso efectivo. Es el resultado de cómo haya funcionado la sociabilidad, especialmente en sus aspectos fundamentales del juego, del humor y del comensalismo festivo, que sostienen los mecanismos de vinculación más básicos de los participantes, al tiempo que manifiestan su voluntad de sustentar el proyecto festivo. Los participantes denominan "estar ahí» a este compromiso de sociabilidad, que es el que "mantiene la llama del fuego" mientras se prepara la Fiesta. Recordemos que, dada la naturaleza lúdica y artística de la sociabilidad, un arte de la existencia cobija y prepara el advenimiento del monumento artístico y del fuego en la Fiesta ${ }^{27}$.

Las formas de la sociabilidad de las fallas tienen una complejidad que desborda esta presentación. Pero voy a referirme a uno de sus elementos más

${ }^{27}$ La sociabilidad festiva, diciéndolo con términos de Heiddegger, es el «cuidar la obra», que se entiende como un saber liberador de apertura del ser para «mantenerse en el interior de la apertura de lo ente acaecida en la obra». Este cuidado no está exento de reflexividad: «Este saber reflexivo es la preparación preliminar y, por lo tanto, imprescindible, para el devenir del arte. Este saber es el único que le prepara a la obra su espacio, que le dispone al creador su camino y al cuidador su lugar» (M. Heidegger, Caminos del bosque, Alianza Universidad, Madrid, pp. 58 y 67). Estas ideas constituyen el núcleo de un esbozo de una teoría de la reflexividad artística, articulada con la Fiesta, que puede encontrarse en X. CosTA, El lugar de la tradicion en la sociología contemporánea, Tesis doctoral, Universidad de Valencia, 1996. 
característicos, que a su vez incluye otros en relación. Las Fallas presentan muchos elementos de los aspectos agónicos, y de competición, del juego. Una gran cantidad de actividades se convierten en algún momento en competiciones. Baste un solo ejemplo: esa forma de exceso, que podríamos calificar de Potlach, que es el monumento mismo, constituye la principal competición entre Fallas. Sin embargo, la forma más pura de esta naturaleza competitiva del juego brota espontáneamente, y está relacionada con la sátira y el humor. Aparece frecuentemente en las tertulias que acompañan la comida y los juegos, aunque es propia de la Fiesta en general. Es muy frecuente tanto en la sociabilidad del casal como en el taller del artista, tanto en horas de trabajo como, especialmente, durante las comidas. Me refiero a la situación de duelo satírico de humor, que los actores denominan "un pique» ${ }^{28}$. Esta situación constituye una tipificación muy característica del humor fallero, cuya forma satírica está presente tanto en la sociabilidad como en las escenas del monumento.

El pique, tal y como se entiende en las Fallas, es un juego de humor consistente en hacer sátira y caricatura del contendiente, esperando respuesta para continuar el intercambio. Los papeles de "víctima", de "atacante» y de "audiencia» van cambiando alternativamente entre los participantes. Cabe decir que presupone confianza, y no puede confundirse con falta de respeto o resentimiento. Diferencia entre los aspectos exteriores, que constituyen la superficie para "picar», y el núcleo esencial de la persona, que inevitablemente se desvela en parte. Los falleros distinguen entre una clase de personas que admite el pique y otra que no. Estas últimas son acusadas de falta de flexibilidad mediante expresiones tales como "no tindre corretja», o "anar a penyó fijo». La práctica del pique satírico adquiere una nueva dimensión cuando se practica el juego al mismo tiempo, particularmente cuando este juego es el truc. Durante una partida el pique se hace más complejo. Entre broma y broma, copa y copa, los compañeros de juego inventan narraciones para ridiculizar las que construye el contrario. Los símbolos, reglas y cartas del juego se convierten en recursos para establecer paralelismos y relaciones imaginativas a varios niveles. Así, por ejemplo, una partida entre músicos de la banda de la Falla, que tocan cornetas y tambores, incorpora una sátira mutua sobre los errores cometidos al tocar el instrumento en el último pasacalle, que se articulan a veces con bromas y alusiones satíricas sobre la eficiencia o ineficiencia sexual de los contendientes. Pero al mismo tiempo la conversación implica constantes comparaciones con otros aspectos, tales como la apariencia física, las "manías» de cada uno, su actividad en la Falla, etc., que se ponen en relación con las formas de gesticulación que implica el juego, con la evolución

${ }^{28}$ Huzinga describe, en Homo Ludens (Alianza, Madrid, 1972), una amplia variedad de juegos de este tipo, situando algunas de ellas en el marco de los Festivales de cambio de solsticio. No es posible dar cuenta de ellas en este contexto. Sin embargo, vale la pena señalar aquí que esta tipificación, a diferencia de la argumentación racional (en Habermas, por ejemplo), constituye una estructura comunicacional, y de reconocimiento inter-subjetivo, que no excluye el juego, el arte y el humor. 
de la partida y con los trucos teatrales inventados para engañar y despistar al contrario.

\section{EL ARTE RETORNA AL FUEGO}

La sociabilidad festiva se intensifica considerablemente durante el período festivo. Las reuniones se multiplican y las comidas, el juego y la broma envuelven todas las actividades. La Fiesta sale a la calle, ensanchando su espacio de juego: los pasacalles, las cabalgatas y las grandes concentraciones de las celebraciones al aire libre proyectan el espíritu festivo hacia el barrio y la localidad. Las calles se transforman mediante la decoración y el constante sonido de la música. La pirotecnia marca el tiempo festivo. La Fiesta prepara ese espacio de juego que demanda un ritual de renovación del mundo y de las cosas. Es la hora de la manifestación pública de aquel saber de apertura que fue sustentado mediante la sociabilidad festiva permanente.

La transición hacia el ritual supone una apropiación festiva del tiempo y del espacio para construir el lugar del «Templo del Fuego», que está moviéndose, siempre abierto al cielo. Música, pirotecnia, flores, vestidos y el movimiento del cuerpo en alegres pasacalles dan ritmo, color y territorio, construyendo el «recinto" y señalando el lugar del altar en la plaza. Se trata de un templo efímero, hecho con materiales perecederos, cuyo denominador común, como en el arte del monumento, es su naturaleza transitoria y fugitiva.

El monumento efímero, que es la Falla, da luz para esa última mirada de la memoria en cada ciclo de la Fiesta. El monumento ilumina aquel espacio de juego al ser erguido y, finalmente, al ser ofrendado. En primer lugar, la falla, como monumento efímero singular, transforma la plaza. Los artistas falleros con experiencia coinciden en señalar que conciben la Falla para la plaza, pensando en una variedad de elementos que inciden en su exposición y cremación: distancias y altura de los edificios, características de las calles que concurren, espacio para el público y pirotecnia, luz, corrientes de aire, etc. Los artistas saben también que la plaza va a convertirse en el lugar de la cosa pública, entendida como arte de la crítica satírica popular. En este sentido las fallas constituyen un modo de comprender la esfera pública, que procede de un modo de representar y levantar un mundo. Los artistas y participantes ven en este carácter artístico de la crítica satírica la diferencia esencial de las Fallas respecto a otras fiestas del fuego. El antiguo pelele, y las primeras representaciones críticas de algunos vecinos del barrio, se han transformado en un elaborado monumento efímero que aborda temas más generales entre los asuntos de actualidad en la vida social. El humor, por otra parte, como ya señaló Freud y explican también los artistas falleros, tiene que ver con la actualidad. El arte crítico y humorístico de la Fiesta cuestiona así frecuentemente el poder establecido. Un artista se refirió a los políticos como sustitutos del antiguo pelele en los siguientes términos: 
"Ahora no tenemos al lechero y a otras figuras parecidas. La leche sale ahora de los tubos de plástico y esto ocurre para todo. Antes se criticaba al lechero, pero ahora la Falla critica cosas como la política internacional. Pero es lo mismo que antes: en vez del lechero ponemos al presidente del Gobierno, Felipe, Aznar o Boyer y Rumasa. Es la actualidad. Por ejemplo, cómo está siendo atacado el planeta, la cantidad de basura que recibe el mar, cómo las empresas contaminan con unos gobiernos que pretenden estar ciegos. Todo esto merece una crítica. Estamos lanzando piedras sobre nuestro propio tejado, y esto es actuar torpemente. Los políticos son manejados por las multinacionales, que son sus jefes. Esto es lo que siempre hemos dicho en las Fallas: que una mano negra maneja a los políticos, que son sus peleles.»

El papel de pharmacos de la sociabilidad festiva, Fiesta, encuentra una correspondencia con otra purificación: la que realiza el fuego. La crítica artística de la Falla, tanto para los artistas como para los participantes, aparece siempre en relación con una catarsis efectiva, con una limpieza y renovación articulada con el fuego. Este destino del monumento, su destrucción por el fuego, le otorga una belleza adicional, que frecuentemente es representada mediante la imagen del Fénix. La crítica de la Fiesta no está así separada de la belleza, de la fantasía y de la ensoñación. Un artista señaló:

«La Falla comienza con un sentido crítico del humor. El contenido de esta crítica es social, económico, político. El sentido de esto es que la Falla se planta, se expone al público y se quema, para nacer inmediatamente de nuevo. Aquí hay una cosa fantástica que algunas personas no comprenden. Es necesario quemar las cosas. Esto no es como la actividad de los bancos, que acumulan las cosas, no, no. Aquí quemamos las cosas para que vuelvan a resurgir de las cenizas. Éste es el sentido interesante de las Fallas, y yo lo encuentro bello.»

La narración humorística de la actualidad que ofrece el monumento no ha perdido la memoria. Las escenas de actualidad aparecen en conjunción con una presentación grotesca del cuerpo humano, articulada con los mitos. Éstos constituyen frecuentemente el centro organizador de las escenas, y presiden el diálogo con la experiencia contemporánea de la política, de la sexualidad, del fuego. La esfera pública de la Fiesta no opone la crítica y el mito ${ }^{29}$. Los artistas

${ }^{29}$ Las fallas cuestionan así el cambio de paradigma propuesto por J. HABERMAS en su Teoría de la acción comunicativa. Habermas asume una oposición entre rituales y mitos, por un lado, y la racionalidad moderna, por el otro. Esto puede observarse a lo largo de toda su obra, pero constituye la presuposición básica de su «hipótesis de la lingüistización de lo sagrado», eje de su cambio de paradigma (Teoría de la acción comunicativa, v. II, Madrid, Taurus, pp. 111 y ss.), así como del "experimento mental» que Habermas propone en las páginas precedentes. Por otro lado, en su introducción a La estructura de la opinión pública, Habermas explícitamente afirma 
muestran una gran confianza en esta persistencia de la mitología: «Ponemos mucha mitología porque los caracteres que han transcendido todas las civilizaciones son mitológicos: el sátiro, la sirena, el centauro. Nunca morirán.» El monumento es, pues, una ocasión para la memoria y el reconocimiento de la comunidad: los símbolos del monumento representan un mundo compartido. De aquí que el monumento pueda realizar aquel papel que Freud asignaba a la poética: la prima de atracción del placer preliminar. El monumento facilita una expresión festiva que da una satisfacción sustitutiva de deseos, dando salida a aspectos de la personalidad que habitualmente laten reprimidos. La naturaleza terapéutica de la sociabilidad festiva y la catarsis del ritual del fuego encuentran aquí un punto de encuentro que multiplica el poder del pharmacos festivo. La memoria vincula el monumento y la sociabilidad, apareciendo como agente de curación. Un participante señaló: "Con esta crítica y con esta excusa [escenas del monumento] hablas de todo durante esos días. Tienes la excusa del monumento, no son cosas que dirías habitualmente, normalmente. Así, en esos días la juerga te lleva a hablar de unos temas que quizá no tratarías ni en broma otras veces, pues te sentirías ridículo o avergonzado.»

Pero la fantasía de la Fiesta todavía proporciona un momento en que una serie de deseos colectivos encuentran manifestación. Los monumentos se queman el 19 de marzo en una Nit del Foc, donde la pirotecnia acerca tiempo y fuego. La fallera mayor consume su poder invitando a la llama a una explosión estruendosa, que marca el fin y el inicio, como condensación del tiempo en fuego ${ }^{30}$. Pero esta invitación deviene aceptación de un destino. La cremà es imparable en esta Nit del foc: el arte se torna fuego de nuevo, y lo glorifica volviendo a su origen. El fuego, y las luces, del hombre, como arte, devienen el fuego del mundo, de las cosas. Las esculturas, como los ya cansados falleros y falleras, misteriosamente devuelven a la tierra su figura y energía: generan infinitas nuevas formas en llamas hasta convertirse en cenizas. Es la experiencia de la finitud. Una fallera señaló: "Quisieras parar el tiempo pero no puedes». Un fallero insistió: "Es una renovación, esa noche todos hemos muerto».

Se trata, además, de un momento de lucidez con respecto a una pérdida, que representa el monumento: «sientes un vacío, y entonces entiendes que el monumento ocupaba un lugar». Hay dos pérdidas: una conocida y la otra sin un claro origen. La primera tiene forma de duelo y la segunda de melancolía.

que la esfera pública plebeya ha desaparecido. Este trabajo proporciona datos para cuestionar ambas presuposiciones. Consiguientemente, Habermas no realiza su cambio de paradigma, al menos en Valencia.

${ }^{30}$ En Fragmentos de una poética del fuego (Paidós, Barcelona, 1992, p. 86) señala Gaston Bachelard, hablando del Fénix como imagen de la resurrección universal: «El Fénix bate las alas, dice un fragmento de la leyenda: ¿Lo hace antes, durante o después del acto ígneo? En ese punto de sublimidad de una combustión del ser no hay más temporalidad. Al batir las alas en su nido, el Fénix es ya un ala de fuego, un fuego que vuela, una llama volátil, un hálito que aviva el fuego. Cuando se va al fondo de la ensoñación, se está seguro de que el fuego tiene alas y de que el ala al sol es una llama viviente. 
La primera se «supera» pronto: una vez se destruye el bello descendiente del parot, el presidente y la Junta directiva dimiten, y se escogen nuevos cargos. La melancolía, manifestada principalmente por la fallera mayor y su corte de honor, tarda un poco más en dejar de expresarse. Pero el saber de esta doble pérdida es de todos, y da al sujeto sentido de su condición. Habitualmente, los teóricos ponen la ley en relación con un duelo, que recuerda el "no matarás». Al enfrentar la melancolía las Fallas muestran que hay una ley más básica, que suele violar el melancólico: «no desearás tu propia muerte». La Fiesta repite cíclicamente un nuevo "curso civilizador", haciendo un recorrido de formación que enseña a escapar de la fusión indiferenciada con la naturaleza y de la pretensión de inmortalidad, para volver a aprender el comienzo de la cultura. Tras esos momentos de ausencia e impotencia, de melancolía compartida, que caracterizan a la cremà, la gente baila en círculo alrededor del fuego. De esa danza de noche, entre briznas de fuego y cenizas, vuelve a surgir la Fiesta.

\section{ABSTRACT}

In the first part of this paper, I deal with some of the aspects which constitute fiestas and art in hermeneutics. The basic idea is that art has its place in the appropriation event (Ereignis), which occurs in the fiesta. In the second part, I situate the festive tradition of Las Fallas (celebration of the feast of St. Joseph) in the context of the ritual transformation of the ancient fire festivals celebrating seasonal change. The ancient mythical connection, which is ambiguous, between the victim and the god, typical of the god's agrarian sacrifice, is now presented in artistic, poematic, and fantastic terms. The victim and the god have become the joint property of art and fire in the fiesta. The care taken by the festive community, which "guards the flame» of the fiesta is understood as sociability (Simmel) in the third section, where I briefly describe the "satiric rivalry" as an example of typification which does not oppose critique of play, art and humour in the processes of recognition inherent in the festive society. Finally, I take a look at the ephemeral monument, its impact on sociability, its public sphere and some collective manifestations, such as pain and melancholy, which take place during the crema, the tragic moment when art is returned to the fire, cyclically repeating a "civilising course» which returns the meaning of the culture to those who participate, and are formed, in the Fiesta. 